ARTICLE

\title{
Hypersexual disorder in general practice
}

\author{
M M Campbell, PhD; D J Stein, FRCPC, PhD \\ Department of Psychiatry and Mental Health, Faculty of Health Sciences, University of Cape Town, South Africa
}

Corresponding author: M M Campbell (mm.campbell@uct.ac.za)

Hypersexual disorder is also termed compulsive sexual disorder, sexual addiction and non-paraphilic sexual disorder, reflecting different approaches to conceptualising its aetiology. Increased frequency of sexual behaviour alone does not indicate pathology. Research suggests that within the population with markedly increased frequency of sexual behaviour, there is a group in whom such behaviour leads to distress and impairment. Patients who experience increased frequency and intensity of sexual behaviour, with accompanying distress and impaired life functioning, may seek medical treatment.

S Afr Med J 2014;104(6):448. DOI:10.7196/SAMJ.8409

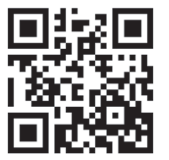

During the most recent revision of the Diagnostic and Statistical Manual of Mental Disorders version 5 (DSM-5), hypersexual disorder was proposed as a new diagnostic category. ${ }^{[1]}$ The submission was ultimately rejected, but in the process a number of useful reviews relating to the assessment and treatment of hypersexual disorder were undertaken. ${ }^{[1-4]}$ In the literature this condition has also been called compulsive sexual disorder, sexual addiction and non-paraphilic sexual disorder, reflecting different approaches to conceptualising its aetiology. ${ }^{[5]}$

\section{Method}

This article presents key findings of recent reviews conducted on hypersexual disorder, focusing on the proposed inclusion of the diagnosis in the DSM-5, ${ }^{[1]}$ assessment (including self-report and clinician-administered measures), ${ }^{[2,4]}$ and treatment options. ${ }^{[2,3]}$

\section{Definition and diagnostic criteria}

$\mathrm{Kafka}^{[1]}$ defines hypersexual disorder as a 'sexual desire disorder characterised by an increased frequency and intensity of sexually motivated fantasies, arousal, urges and enacted behaviour in association with an impulsivity component' that causes significant personal distress or impairment and is not caused by the physiological effect of a drug-related substance.

Proposed diagnostic criteria ${ }^{[1]}$ include at least three of the following experienced over a 6-month period:

- Time consumed by sexual fantasies, urges or behaviours that repetitively interfere with other important (non-sexual) goals, activities and obligations.

- Repetitive engaging in sexual fantasies, urges or behaviours in response to dysphoric mood states (e.g. anxiety, depression, boredom, irritability).

- Repetitive engaging in sexual fantasies, urges or behaviours in response to stressful life events.

- Repetitive, but unsuccessful, efforts to control or significantly reduce these sexual fantasies, urges or behaviours.

- Repetitive engaging in these sexual behaviours, while disregarding the risk of physical or emotional harm to self or others.
Proposed specifiers include excessive masturbation, pornography use, sexual behaviour with consenting adults, cybersex, telephone sex, strip clubs, and other. ${ }^{[1]}$

\section{Epidemiology}

Research has provided evidence for a population characterised by increased frequency of sexual behaviours. For example, within a sexuality survey of US men aged 18 - 59 years $(N=1320)$ only $1.9 \%$ reported masturbating daily and only $7.6 \%$ reported sexual intercourse with their partners $\geq 4$ times per week. ${ }^{[1,6]}$ In a general population sample of 2450 Swedish men and women, only $12.1 \%$ of men reported $\geq 4$ orgasms a week, and only $6.8 \%$ of women reported $\geq 3$ orgasms a week. ${ }^{[1,7]}$ In comparison, $90 \%$ of a sample of US men receiving treatment for paraphilia-related conditions reported $\geq 5$ orgasms per week..$^{[1,8]}$

However, increased frequency of sexual behaviour alone does not indicate pathology. ${ }^{[9]}$ Research also suggests that within this population there is a group in whom such behaviour leads to distress and impairment. Within this group increased frequency and intensity of sexual behaviour is associated with increased risk-taking behaviour, dissatisfaction in sexual relationships, interpersonal difficulties, sexually transmitted infections (STIs) and accessing professional services for sexuality-related problems. ${ }^{[7]}$

Patients who experience increased frequency and intensity of sexual behaviour, with accompanying distress and impaired life functioning, may seek medical treatment. When diagnosing patients who present with such behaviours, the DSM system requires clinicians to use a different specified diagnosis. ${ }^{[10]}$ For the International Classification of Diseases-11 (ICD-11), however, it has been proposed that compulsive sexual disorder be included as one of the impulse control disorders. ${ }^{[11]}$

A diagnosis such as hypersexual disorder or compulsive sexual disorder may assist clinicians in patient care by providing a set of clinical criteria. In addition, such a diagnosis would provide agreedupon terminology and features that may encourage epidemiological and clinical research, ultimately improving the quality of research about hypersexual disorder and its treatment. ${ }^{[9]}$ The diagnosis would also arguably encourage the development of standardised psychometric instruments to assess nosological criteria and symptom severity. While 
numerous instruments for measuring sexual behaviour are currently in use ${ }^{[4]}$ only the Hypersexual Behaviour Inventory (HBI), drawing directly from the hypersexual disorder diagnostic criteria proposed for the DSM-5, provides a clinical cut-off score for the diagnosis. ${ }^{[12]}$

\section{Differential diagnosis}

In making the diagnosis of hypersexual disorder, it is important firstly to differentiate the disorder from normal sexual behaviour. ${ }^{\left[{ }^{[0]}\right.}$ Because there is no consistent, normative pattern of sexual behaviour cross-culturally, a diagnosis of hypersexual disorder arguably has the risk for pathologising adaptive human behaviour. ${ }^{[2,13]}$ Secondly, it is important to ensure that the diagnosis is not due to another underlying psychiatric or general medical disorder. ${ }^{[9,14]}$ Patients with bipolar disorder, for example, may present with hypersexuality. ${ }^{[2]}$

\section{Pathogenesis}

Different pathophysiological models have been proposed for conceptualising the aetiology of hypersexual disorder, including a sexual desire dysregulation model, a sexual addiction and dependency model, and sexual compulsivity and impulsivity models. ${ }^{[1,5]}$ These different models are associated with different terminology and assessment tools, making it difficult to find consensus in the field. ${ }^{[2]}$ Furthermore, critics have challenged the scientific rigor of the epidemiological and clinical data currently available on hypersexual disorder ${ }^{[2,3,14]}$ Although further work is therefore needed, the different theoretical models and empirical datasets have each contributed to a better understanding of the disorder.

\section{Assessment}

Patients with hypersexual disorder will most likely enter the healthcare system through their family practitioner. These clinicians may already have established a trusting rapport, and so be in a position to support the patient and family during the treatment process. ${ }^{[15]}$ Furthermore, the family practitioner may play a preventive role in identifying patients who may potentially be at risk of developing hypersexual disorder as a result of childhood trauma. ${ }^{[15]}$

The clinical assessment includes a thorough clinical interview eliciting information about the history of the presenting problem, the patient's sexual, medical, psychiatric, substance-use, mental health and psychosocial history, with a particular focus on comorbid anxiety and depression. ${ }^{[2]}$ Additional information from family members and intimate partners may provide valuable collateral information. Importantly, patients with this disorder may present with comorbid psychiatric conditions, including anxiety and mood disorders, substance-use disorders, attention deficit hyperactivity disorder, personality disorders and paraphilias. ${ }^{[1,2]}$

The clinical assessment should cover the relevant symptoms and the resulting distress and impairment. Hypersexual disorder is associated with preoccupation with sexual fantasies and sexual behaviours, pornography dependency, compulsive masturbation, promiscuity, and risk-taking and sensation-seeking sexual behaviour. ${ }^{[1,2]}$ Consequently, patients may have an increased risk of unprotected sex, leading to possible STIs, including HIV infection, and unwanted pregnancies. ${ }^{[1,2]}$ Patients may also report interpersonal and relationship problems, including marital separation and divorce, excessive financial expenses, work and education impairments. ${ }^{[1,2]}$

\section{Treatment}

There is some evidence for the value of both pharmacotherapy and psychotherapy in the treatment and support of patients with hypersexual disorder. ${ }^{[2]}$

\section{Pharmacotherapy}

Two double-blind, placebo-controlled trials have shown a decrease in hypersexual disorder symptoms with the use of antidepressant medication (desipramine and clomipramine). ${ }^{[16,17]}$ There are also case series reporting potential benefits of selective serotonin re-uptake inhibitors, psychostimulants and triptorelin in hypersexual disorder ${ }^{[2]}$ Case reports have documented the successful treatment of hypersexual disorder with naltrexone, nefazodone and valproic acid. ${ }^{[2]}$ However, no medication has been registered for this condition.

\section{Psychotherapy}

While different psychotherapy modalities have been proposed for the treatment of hypersexual disorder, placing emphasis on different aspects of the patient's presenting problem, ${ }^{[2]}$ there are few data from controlled trials to demonstrate the efficacy of these approaches.

\section{Conclusion}

There is growing recognition of hypersexual disorder in the literature, and while some empirical research is available, more is needed. Family practitioners are very likely to encounter patients with hypersexual disorder, although this may not be the presenting complaint. A thorough clinical assessment is necessary to support these patients and to ensure that they receive appropriate care. Hypersexual disorder is associated with HIV infection and STIs because of the high-risk sexual practices of these patients, and sexual health screenings form one essential part of their healthcare. Referral for specialised pharmacotherapy and psychotherapy is possible in some centres.

Acknowledgement. Prof. D J Stein is supported by the Medical Research Council of South Africa.

\footnotetext{
References

1. Kafka MP. Hypersexual disorder: A proposed diagnosis for DSM-V. Arch Sex Behav 2010;39(2):377400. [http://dx.doi.org/10.1007/s10508-009-9574-7]

Kaplan MS, Krueger RB. Diagnosis, assessment, and treatment of hypersexuality. I Sex Res 2010;47(2-3):181-198. [http://dx.doi.org/10.1080/00224491003592863]

3. Hook JN, Reid RC, Penberthy JK, Davis DE, Jennings DJ. Methodological review of treatments for nook JN, Reid RC, Penberthy JK, Davis DE, Jennings DJ. Methodological review of treatments for
nonparaphilic hypersexual behavior. J Sex Marital Ther 2014;40(4):294-308. [http://dx.doi.org/10.10 nonparaphilic hypersexual b

Derogatis LR. Assessment of sexual function/dysfunction via patient reported outcomes. Int J Impot 4. Derogatis LR. Assessment of sexual function/dysfunction vi
Res 2008;2:35-44. [http://dx.doi.org/10.1038/sj.ijir.3901591]

Res 2008;2:35-44. [http://dx.doi.org/10.1038/sj.ijir.3901591]
5. Stein DJ, Black DW, Pienaar W. Sexual disorders not otherwise specified: Compulsive, addictive, or impulsive? CNS Spectrums 2000;5(1):60-64.

6. Laumann EO, Gagnon JH, Michael RT, Michaels S. The Social Organization of Sexuality: Sexual Practices in the United States. Chicago: University of Chicago Press, 1994.

7. Langstrom N, Hanson RK. High rates of sexual behavior in the general population: Correlates and predictors. Arch Sex Behav 2006;35:37-52. [http://dx.doi.org/10.1007/s10508-006-8993-y]

8. Kafka MP. Hypersexual desire in males: An operational definition and clinical implications for men with paraphilias and paraphilia-related disorders. Arch Sex Behav 1997;26:505-526. [http://dx.doi. org/10.1023/A:1024507922470]

9. Stein D, Black DW, Shapira NA, Spitzer RL. Hypersexual disorder and preoccupation with internet pornography. Am J Psychiatry 2001;158(10):1590-1594. [http://dx.doi.org/10.1176/appi. ajp.158.10.1590]

. American Psychiatric Association. Diagnostic and Statistical Manual of Mental Disorders. 5th ed. Text American Psychiatric Association. Diagnostic and Statistical Manu
revision. Washington, DC: American Psychiatric Association, 2014.

11. Grant JE, Atmaca M, Fineberg NA, et al. Internet and other proposed addictive behaviors in the Grant JE, Atmaca M, Fineberg NA, et al. Internet and other propose
International Classification of Diseases-11. World Psychiatry (in press).

12. Reid RC, Carpenter BN, Lloyd TQ. Assessing psychological symptom patterns of patients seeking help for hypersexual behavior. Sexual and Relationship Therapy 2009;24:47-63. [http://dx.doi. org/10.1080/14681990802702141]

13. Winters J. Hypersexual disorder: A more cautious approach. Arch Sex Behav 2010;39:594-596. [http:// dx.doi.org/10.1007/s10508-010-9607-2]

4. Moser C. Hypersexual disorder: Just more muddled thinking. Arch Sex Behav 2010;40:227-229. [http://dx.doi.org/10.1007/s10508-010-9690-4]

15. Borgermans L, Vrijhoef B, Vandevoorde J, De Maeseneer J, Vansintejan J, Devroey D. Relevance of hypersexual disorder to family medicine and primary care as a complex multidimensional chronic disease construct. Int J Fam Med 2013; Epub 27 August 2013. [http://dx.doi.org/10.1155/2013/519265]

16. Kruesi MJP, Fine S, Valladares L, Phillips RA, Rapoport JL. Paraphilias: A double-blind crossover comparison of clomipramine versus desipramine. Arch Sex Behav 1992;21:587-593. [http://dx.doi. comparison of clomiprami
org/10.1007/BF01542257]

17. Wainberg ML, Muench F, Morgenstern J, et al. A double-blind study of citalopram versus placebo in the treatment of compulsive sexual behaviors in gay and bisexual men. J Clin Psychiatry 2006;67:19681973. [http://dx.doi.org/10.4088/JCP.v67n1218]
} 